\title{
Resource Schedule of Concrete Fish Pond Construction Using Network Analysis
}

\author{
Akomolafe A. A. \\ Department of Statistics, Federal University of Technology, Akure, Ondo state, Nigeria
}

\begin{abstract}
In the construction of building, preparation of bid, maintenance and planning of oil refinery and preparation for agricultural activities, there is a need to know the completion days of the project without delay and the earliest time and the latest time for which each activity will take. It was based on this that we decide to analyze the construction of concrete fish pond using Network Analysis through the use of Critical Path Method (CPM) and Program Evaluation Review Technique (PERT). Sixty-four days was arrived at for the completion of the construction using CPM while sixty-eight days with $99 \%$ probability was arrived at using PERT method. In deciding which of the method is best suitable for the construction of the fish pond, PERT serve as the best method due to the fact that it considers the Pessimistic Time (longest time possible and can be seen as usual delay) and Optimistic Time (shortest time possible if things go perfectly) as well as the probability [which is $99 \%$ ] of completing the task within a specific time. The result established some useful facts for researchers in this area as well as managers of industry in carrying out their study from the feasibility stage to the other stages so as to have a good practical target towards the completion of the project as planned.

Keyword: Network Analysis, Critical Path Method, Program Evaluation Review Technique, Pessimistic Time, Optimistic Time and Probability
\end{abstract}

DOI: $10.7176 / \mathrm{JMCR} / 57-04$

Publication date:June $30^{\text {th }} 2019$

\section{INTRODUCTION}

Network Analysis is the general name given to certain specific techniques which can be used for the planning, management, and control of project, project itself can be defined as a temporary endeavor undertaken to create a "unique" product or service e.g. Construction of a building or highway, preparation of bid, maintenance and planning of oil refinery, development of new weapon system. Network Analysis is divided into two core branches namely Critical Path Method (CPM) and Program Evaluation and Review Technique (PERT). CPM is commonly used with all forms of projects, including construction, aerospace and defense, software development, research projects, product development, engineering, and plant maintenance, among others. Any project with interdependent activities can apply this method of mathematical analysis. Although the original CPM program and approach is no longer used, the term is generally applied to any approach used to analyze a project network logic diagram. Project Evaluation and Review Techniques is commonly abbreviated to PERT. PERT is a method of analyzing the tasks involved in completing a given project, especially the time needed to complete each task, and to identify the minimum time needed to complete the total project. It incorporates uncertainty by making it possible to schedule a project while not knowing precisely the details and durations of all the activities. It is more of an event-oriented technique rather than start- and completion-oriented, and is used more in projects where time is the major factor rather than cost. It is applied to very large-scale, one-time, complex, non-routine infrastructure and Research and Development projects. Program Evaluation Review Technique (PERT) offers a management tool, which relies "on arrow and node diagrams of activities and events: arrows represent the activities or work necessary to reach the events or nodes that indicate each completed phase of the total project." For example, figure 1 shows how network diagram look like

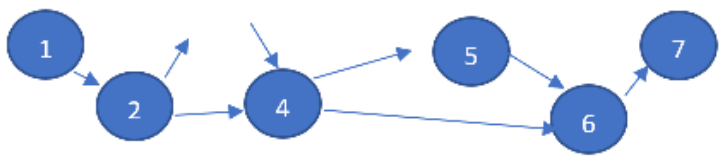

FIGURE 1: Example of a network

We use Critical Path Method (CPM) when the activities values are known or deterministic while Program Evaluation and Review Technique (PERT) is used when the activities are probabilistic in nature.

\section{LITERATURE REVIEW}

The Critical Path Method and Program Evaluation and Review Technique is a fundamental technique developed for project management assuming under the unlimited resource availability. In real life project activities must be schedule under the limited resource; such as limited crew sizes, limited equipment amounts and limited materials. The practical problem of allocating resources over the time to perform collective tasks arises in a variety of 
situation and frequency the scheduler must take account of the trade-off between availability of resources and activity duration. The scheduling of tasks and the allocation of resources in medium to large schedule projects is an extremely hard problems and challenges of project management due to its complexity. The resource constrained project scheduling problem (RCPSP) is one of the most classical scheduling problems.

Solving in heuristic methods based on the serial and parallel scheduling generation schemes procedures make feasible solution to handle practical resource constrain project scheduling problem. Many heuristic approaches have been proposed in RCPSP. Ulusoy and Ozdamar (1995) made a comparable analysis on projects through parallel methods using different priority rules with non-renewable resources. In parallel method algorithms it takes multiple project decision criteria (resource constraints, activity duration, slack, latest finish, etc). Thomos and Lova (2003) developed an effective multi-pass heuristic for project scheduling with resource constraints problem. Tormos and Lova (2001) described a hybrid multi-pass competitive heuristic solution technique for resource constrained project scheduling problem. They combined random sampling procedure with a forward and backward scheduling technique. They compared against the best availably heuristic using PSPLIB (Kolisch 1995, Kolisch and Sprecher 1996), the algorithm gives the best heuristic solution as compare with other algorithm for the RCPSP.

Hong et al. (2001) presented a resource allocation point that took into account the dynamic and stochastic characteristics of simulation system for the proposed of processing a decision making ability. Herroelen and Leus (2004) have dropped the hypothesis of unrestricted resource availability by using a resource flow network for robust resource allocation to a feasibility baseline scheduling. Valls et al. (2003) developed a hybrid genetic algorithm with forward - backward improvement of activity list based genetic algorithm. Thomos and Lova (2001) developed an iterative forward-backward heuristic. Their approach used by serial or parallel schedule generation scheme (SGS) by means of regret-biased sampling method with the latest finish time priority rule.

\section{META-HEURISTIC APPROACHES}

There are meta-heuristic approaches like genetic algorithms, tabu search, simulated annealing and ant colony systems are describe for the solution of RCPSP. Genetic algorithms are stochastic search based upon the mechanism of natural selection and population genetics. Holland (1975) was developed genetic algorithms (GA) based on mechanism of natural selection in biological system. It uses random direct search by the process of genetic evolution and principle of "survival of fittest". Feng et al. (1997), Li et al. (1999) applied successfully genetic algorithm for construction scheduling for time-cost trade-off problems. Hindi et al. (2002) developed a genetic algorithm employed the activity representation with serial SGS. Thomas and Salhi (1998) introduced a tabu search directly on scheduling by defining three different moves. Glover and Kochenberger (2003) employed the tabu search (TS) method to overcome regional optimized solution by multiple regional searches and the method depended on the ability of the flexible memory frame to sequentially record moving decisions from different cycles.

Valls et al. (2003) implemented a new heuristic algorithm with concept of tabu search within explicitly using memory structure embedded in a population based framework. Klein (2000) developed tabu search method for the RCPSP with time varying resource constraints. It is based on activity list representation and the same SGS. The procedure called RETAPS (Reactive Tabu

Search for Project Scheduling). Nonobe and Ibaraki (2002) suggested a tabu search approach for a generalized variant of the RCPSP. In this activities list presentation approach, the serial SGS and a specific neighborhood reduction mechanism are employed. Cho and Kim (1997) applied simulated annealing algorithm for RCPSP. Thomas and Salhi (1998) introduced tabu search method which operates directly on scheduling. The solution of simulated annealing and tabu search gives best solution then the genetic algorithm. Bouleimen and Lecocq (1996) developed a simulated annealing algorithm for multi-mode resource constraints project scheduling problem. Dorigo et al. (1996) employed ant colony optimization (ACO) imitates an ant movement to find an optimal solution. The main objective of ant system include positive feedback for discovery of good solutions computation avoid premature convergence, use of constructive heuristic and help acceptable solution in early stage of the search process. Based on the simulation result, the ant colony optimization (ACO) is robust and can be used in RCPSP for optimization solution.

\section{METHODOLOGY}

Both Critical Path Method and Program Evaluation and Review Technique are network based techniques. They are vital tools in the planning, scheduling, and control of projects. Once you have the information a network can be created showing the precedence relationship. The next step involves specific computations to develop a time schedule for the project.

\subsection{CONSTRUCTING THE NETWORK}

Each activity is represented by an arc pointing in the direction of progress. The nodes establish precedence relationships among different activities. There are three rules for constructing the network: 
1.Each activity is represented by one, and only one, arc.

2.Each activity must be identified by two distinct end nodes.

3. Maintain correct precedence relationship as you add activities to network.

The following must be considered: what activities must immediately precede the current activity: what activities must follow the current activity and what activities must occur concurrently with current activity?

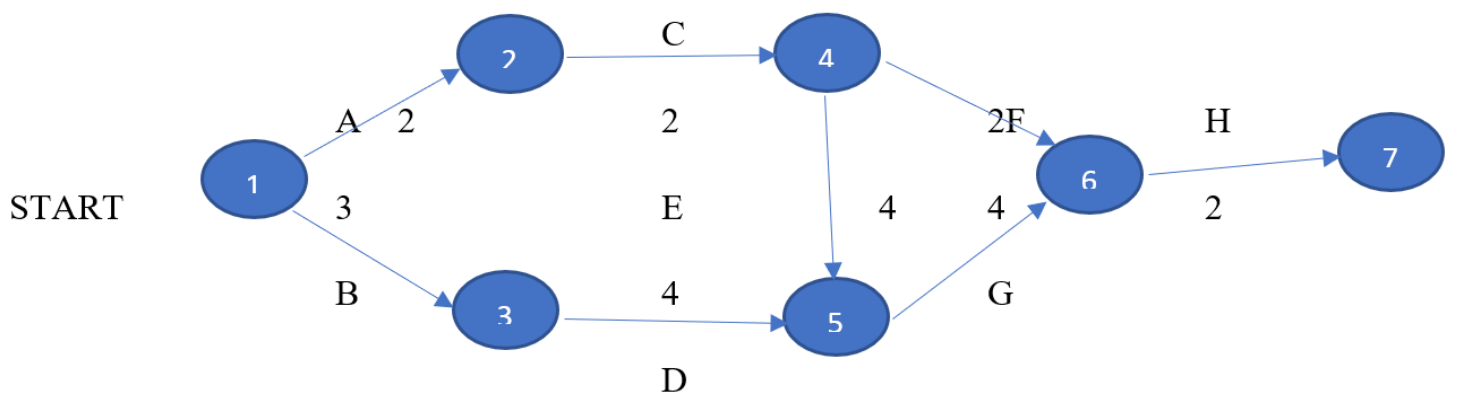

FIGURE 2: Arrow diagram network

\subsection{CRITICAL PATH METHOD (CPM) COMPUTATIONS}

A critical activity is an activity that has no leeway in determining its start and finish times. If a critical activity runs late, then the entire project will run late. A noncritical activity is an activity that allows some scheduling slack, meaning it can be advanced or delayed (within limits) without affecting the completion time of the project. An event is defined as a point in time when activities are completed and another activity is started. In terms of a network, an event corresponds to a node.

$\mathbf{E j}=$ Earliest occurrence time of event $\mathbf{j} . \quad \mathbf{L j}=$ latest occurrence time of event $\mathbf{j}$.

Dij $=$ Duration of activity.

The critical path calculations involve two passes: The forward pass determines the earliest occurrence times of the event, and the backward pass calculates their latest occurrence times.

FORWARD PASS (EARLIEST OCCURRENCE TIMES).

The computation starts at node 1 and advance recursively to end node $\mathrm{n}$.

Step 1: Set $E 1=0$ (indicates the project starts at node 1 and time 0 ). The first node of the network will never have any nodes going into it, so that is why it will always be zero.

Step 2: Given that nodes $\mathbf{p}, \mathbf{q}, \ldots$, and $\mathrm{v}$ are linked directly to node $\mathrm{j}$ by incoming activities $(\mathbf{p}, \mathbf{j}),(\mathbf{q}, \mathbf{j}), \ldots$, and $(\mathbf{v}, \mathbf{j})$ and that the earliest occurrence times of events (nodes) $\mathbf{p}, \mathbf{q}, . .$. , and $\mathrm{v}$ have already been computed, then the earliest occurrence time of event jis computed as

$$
\mathbf{E j}=\max \{\mathbf{E p}+\mathbf{D p j}, \mathbf{E q}+\mathbf{D q j}, \ldots, \mathbf{E v}+\mathbf{D v j}\}
$$

Step 3: Calculate $\mathbf{E j}$ for every node until you reach the final node, $\mathbf{n}$.

BACKWARD PASS (LATEST OCCURRENCE TIMES LJ).

Once you have computed the forward pass, the backward pass computations start at the final node $\mathrm{n}$ and end at node 1.

Step 1: Set $\mathbf{L n}=\mathbf{E n}$ (indicates that the earliest and latest occurrence of the last node of the project are the same.

Step 2: Given that nodes $\mathbf{p}, \mathbf{q} \ldots$ and $\mathrm{v}$ are linked directly to node $\mathbf{j}$ by outgoing activities

$(\mathbf{j}, \mathbf{p}),(\mathbf{j}, \mathbf{q}), \ldots, \mathbf{( j ,}, \mathbf{v})$ and that the latest occurrence times of events (nodes) $\mathbf{p}, \mathbf{q}, \ldots .$. , and $\mathbf{v}$ have already been computed, then the latest occurrence time of event $\mathbf{j}$ is computed as

$$
\mathbf{L j}=\min \{\mathbf{L p}+\mathbf{D j p}, \mathbf{L q}+\mathbf{D j} \mathbf{j}, \mathbf{, L v}+\mathbf{D j} \mathbf{v}\}
$$

Step 3: Calculate $\mathbf{E j}$ for every node until you reach the final node, $\mathrm{n}$.

Based on the preceding calculations, an activity $(\mathbf{i}, \mathbf{j})$ will be critical if it satisfies three conditions:
1) $\mathbf{L i}=\mathbf{E} \mathbf{i}$
2) $\mathbf{L j}=\mathbf{E} \mathbf{j}$
3) $\mathbf{L j}-\mathbf{L i}=\mathbf{E} \mathbf{j}-\mathbf{E} \mathbf{i}=\mathbf{D} \mathbf{i j}$

The three conditions state that the earliest and latest occurrence times of end nodes $\mathbf{i}$ and $\mathbf{j}$ are equal and the duration Dij fits "tightly" in the specified time span. An Activity that does not satisfy all three conditions is thus noncritical. By definition, the critical activities of a network must constitute an uninterrupted path that spans the entire network from start to finish.

DETERMINATION OF THE SLACKS $\left(\boldsymbol{S}_{I J}\right)$.

Slack times give you the amount of time an activity can run late without delaying your project. Consequently, a slack time of zero identifies a critical activity.

$$
\text { Sij }=\text { Lj- Ei - Dij }
$$

\subsection{PROGRAM EVALUATION AND REVIEW TECHNIQUE (PERT) COMPUTATIONS}

PERT differs from CPM in that it bases the duration of an activity on three estimates: 
1. Optimistic time, a, which occurs when execution goes extremely well.

2. Most likely time, $\mathrm{m}$, which occurs when execution is done under normal conditions.

3. Pessimistic time, $b$, which occurs when execution goes extremely poorly.

The PERT method was motivated by the assumption that the activity time was a random variable with a beta distribution. Unlike the normal distribution, which has an infinite range and is symmetrical, the beta distribution has a minimal and maximum value, and is capable of assuming a wide variety of shapes.

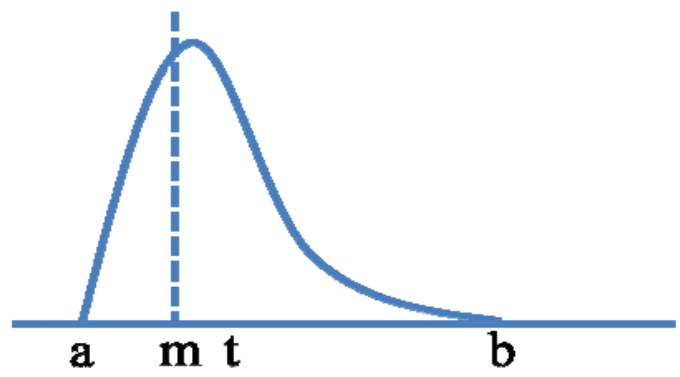

FIGURE 3: Graph of Beta Distribution

Note: the estimate is a weighted average of the values of $\mathbf{a}, \mathbf{m}$, and $\mathbf{b}$, where the weights sum to 1 . This means that the estimate will always lie between $\mathbf{a}$ and $\mathbf{b}$. The standard deviation of an activity time is estimated by assuming that there are six standard deviations between the optimistic and pessimistic times. Once we compute the standard deviation we can compute the variance of the activity by $\operatorname{Var}_{\mathbf{i j}}=(\mathbf{i j})^{\mathbf{2}}$

The purpose of PERT is to analyse the probability that a critical path will be finished by any given time. The analysis proceeds as followed:

1) Let $T$ equal the total time that will be taken by the activities on a critical path.

2) Find the probability that the value of $T$ will turn out to be less than or equal to any specified value of interest.

The activity times are independent random variables. This is a valid assumption for most PERT networks and the random variable $\mathrm{T}$ has an approximately normal distribution. This assumption relies on the central limit theorem, which in broad terms states that the sum of independent random variables is approximately normally distributed. Then $\mathbf{T} \leq \mathbf{2 2}$, we will want to convert $\mathbf{T}$ to a standard normal random variable and use a $Z$ table. The first step is to find the standard deviation of $\mathbf{T}$ (standard deviation of the path). To do this we need the variance of $\mathbf{T}$ (variance of the path). To find the variance of a path, we add all the variance for a path we wish to take. For example, if we have a path consisting of activities starting at activity $\mathbf{A}$ and finishing at activity $\mathbf{D}$, such that, $\mathbf{A} \rightarrow \mathbf{B} \rightarrow \mathbf{C} \rightarrow \mathbf{D}$, and we wish to find the probability that we can complete activity $\mathbf{D}$ within $\mathbf{5}$ days, we will need to know the standard deviation of the path, but to do that we must know the variance of the path. The variance of the path is just calculated by adding the variance of each activity.

$\operatorname{Var} \mathbf{T}=(\operatorname{var}$ for activity $\mathbf{A})+($ var for activity $\mathbf{B})+($ var for activity $\mathbf{C})+($ var for activity $\mathbf{D})$

We can now calculate the standard deviation of the path, which is simply: $\sqrt{\boldsymbol{v a r}} \boldsymbol{T}$. Finally, we now need to convert $\mathbf{T}$ to a standard normal random variable, $\mathbf{Z}$, in the usual way: $\mathbf{Z}=\mathbf{T}-\boldsymbol{\mu} / \boldsymbol{\sigma}$. Recall that $\mu$ is mean (the expected completion time). We now use the $\mathbf{Z}$ score to calculate the probability.



FIGURE 4: Example of PERT Network

\section{DATA ANALSIS AND RESULTS}


This research work is based on the Network Analysis of Concrete Fish Pond Construction (case study of OgunOshun River Basin Development Authority), we focus on application of a statistical concept to real life problem. It is a method that can be trusted if one desire to construct a project and immediately see how the use of CPM and PERT could help in managing such a project.

\subsection{CRITICAL PATH METHOD (CPM)}

To start with Activity A, Site Clearing and levelling, and finishes upon completion of Activity L. Using the rules, we begin by computing the Earliest Occurrence Times (Forward Pass). Once all Earliest Occurrence Times are calculated we can start computing our Latest Occurrence Time, then using a backwards pass to calculate all. Latest Occurrence Times. Slack times are calculated using both the Earliest Occurrence Time and Latest Occurrence Times. The slack time computations tell us which activities are critical-have a slack time of zero, and which activities are non-critical - have a slack time greater than zero. The critical path is a path on the network from the start node to finish node, which contain slack times of zero. Note that there can be more than one pass, and a critical path can contain a dummy activity.

TABLE 1: SCHEDULED WORK PROGRAMME FOR THE CONSTRUCTION OF CONCRETE FISH POND $(10 \mathrm{~m} \times 10 \mathrm{~m})$ AT PLOT 22 , ALABATA ROAD, ABEOKUTA, OGUN STATE.

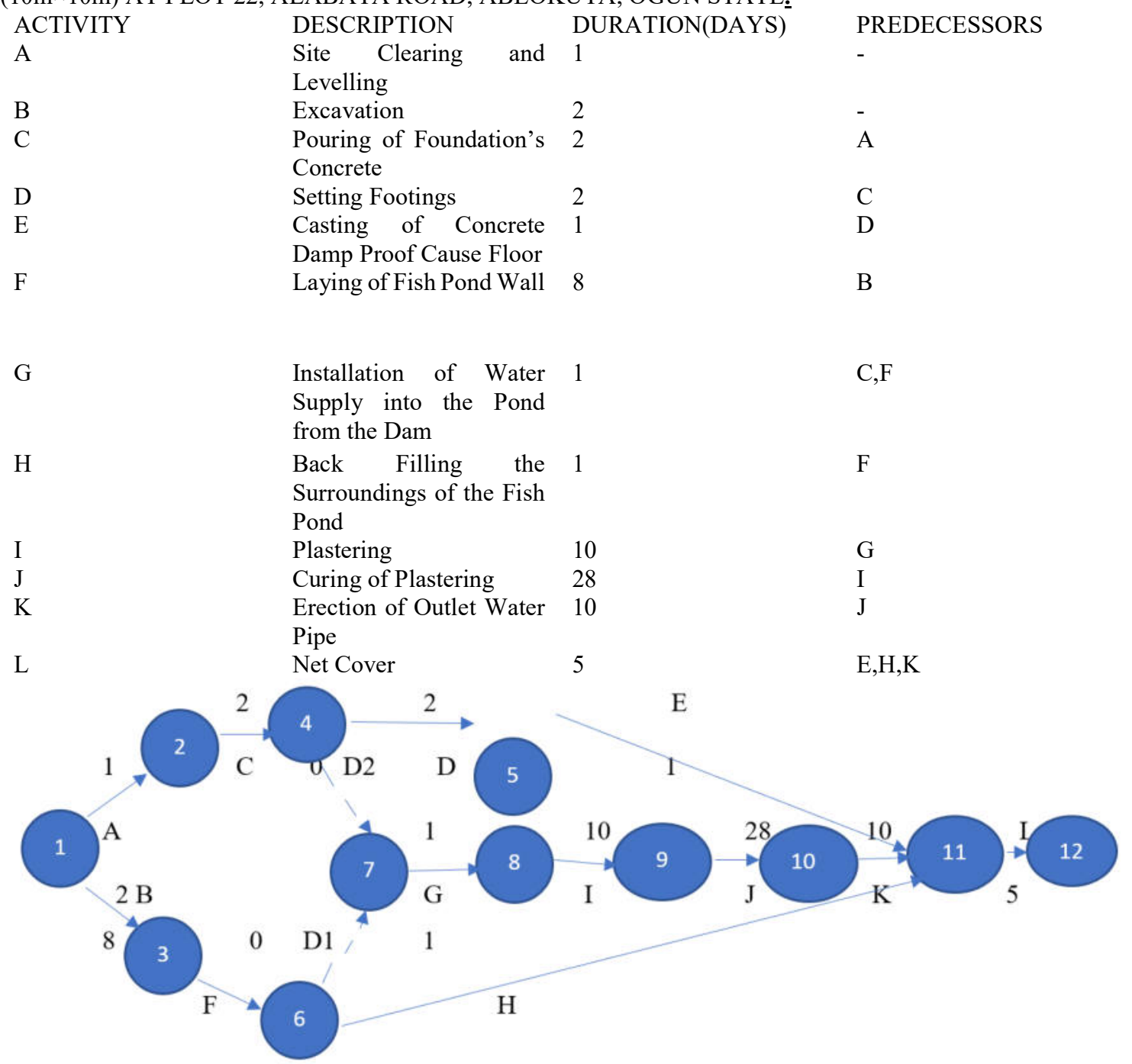

FIGURE 5: NETWORK ANALYSIS FOR THE CONSTRUCTION OF CONCRETE FISH POND

We calculate the Earliest Occurrence Time, $\mathbf{E j}$, by doing a forward pass. So, set $\mathbf{E} \mathbf{1}=\mathbf{0}$. Since there is only one arc coming into node 2 (from node A) the earliest occurrence time to $\mathbf{E 2}=\mathbf{1}$. If $\mathbf{E j}$ has more than one arc coming in to it, $\mathbf{E} \mathbf{j}=$ maximum of sums $(\mathbf{E i}+\mathbf{T i j})$ coming into $\mathbf{E} \mathbf{j}$, below lies all the computation of the earliest time using CPM: 


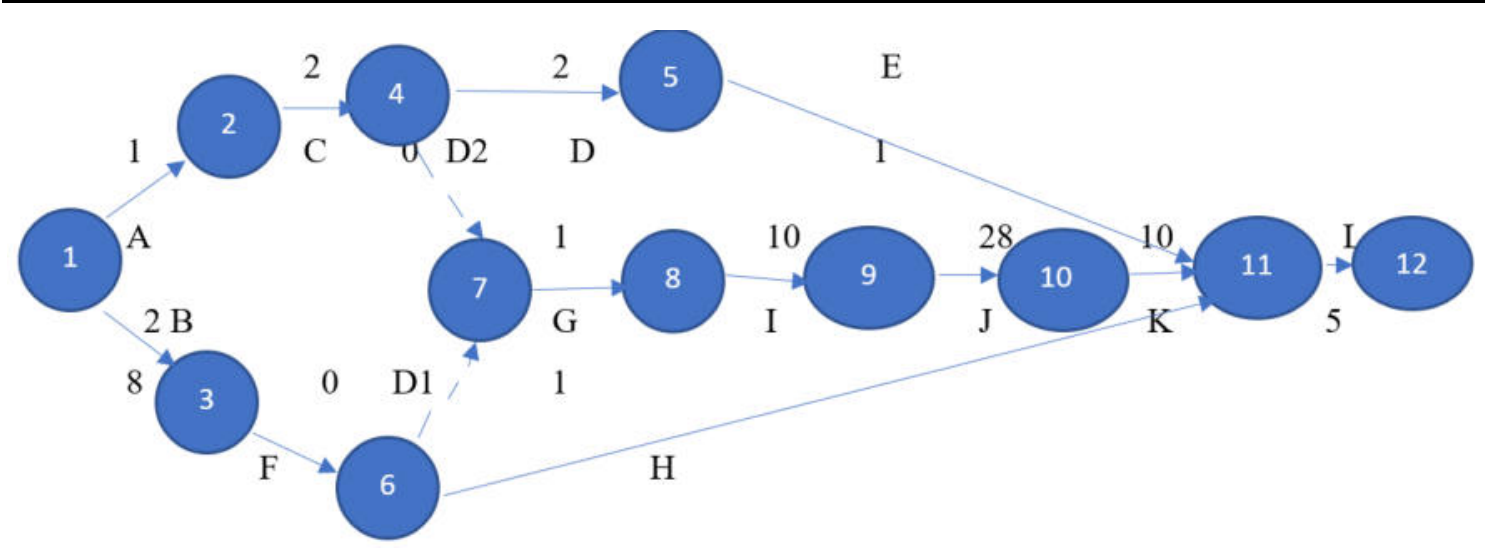

FIGURE 6: Network for the computation of the earliest time using CPM where
$\mathrm{ET}_{1}=0$,
$\mathrm{ET}_{2}=\operatorname{MAX}\left(\mathrm{ET}_{1}, \mathrm{ET}_{1}+\mathrm{a}_{12}\right)=(0,0+1)=1$
$\mathrm{ET}_{3}=\operatorname{MAX}\left(\mathrm{ET}_{1}, \mathrm{ET}_{1}+\mathrm{a}_{13}\right)=(0,0+2)=2$
$\mathrm{ET}_{4}=\operatorname{MAX}\left(\mathrm{ET}_{2}, \mathrm{ET}_{2}+\mathrm{a}_{24}\right)=(1,1+2)=3$
$\mathrm{ET}_{5}=\operatorname{MAX}\left(\mathrm{ET}_{4}, \mathrm{ET}_{4}+\mathrm{a}_{45}\right)=(3,3+2)=5$
$\mathrm{ET}_{6}=\operatorname{MAX}\left(\mathrm{ET}_{3}, \mathrm{ET}_{3}+\mathrm{a}_{36}\right)=(2,2+8)=10$
$\mathrm{ET}_{7}=\mathrm{MAX}\left(\mathrm{ET}_{4}+\mathrm{a}_{47}, \mathrm{ET}_{6}+\mathrm{a}_{67}\right)=(3+0,10+0)=10$
$\mathrm{ET}_{8}=\operatorname{MAX}\left(\mathrm{ET}_{7}, \mathrm{ET}_{7}+\mathrm{a}_{78}\right)=(10,10+1)=11$
$\mathrm{ET}_{9}=\operatorname{MAX}\left(\mathrm{ET}_{8}, \mathrm{ET}_{8}+\mathrm{a}_{89}\right)=(11,11+10)=21$
$\mathrm{ET}_{10}=\operatorname{MAX}\left(\mathrm{ET}_{9}, \mathrm{ET}_{9}+\mathrm{a}_{910}\right)=(21,21+28)=49$
$\mathrm{ET}_{11}=\operatorname{MAX}\left(\mathrm{ET}_{5}+\mathrm{a} 5_{11}, \mathrm{ET}_{10}+\mathrm{a}_{1011}, \mathrm{ET}_{6}+\mathrm{a}_{611}\right)=(5+1,49+10,10+1)=59$
$\mathrm{ET}_{12}=\operatorname{MAX}\left(\mathrm{ET}_{11}, \mathrm{ET}_{11}+\mathrm{a}_{1112}\right)=(59+5,59)=64$

below lies the computation of latest time:

(ET, LT)

$\mathrm{ET}=$ Earliest time

LT $=$ Latest time



$\mathrm{LT}_{12}=\mathrm{ET}_{12}=64$

FIGURE 7: NETWORK WITH EARLIEST TIMES

$\mathrm{LT}_{11}=\operatorname{MIN}\left(\mathrm{LT}_{12}, \mathrm{LT}_{12}-\mathrm{a}_{1112}\right)=(64,64-5)=59$

$\mathrm{LT}_{10}=\operatorname{MIN}\left(\mathrm{LT}_{11}, \mathrm{LT}_{11}-\mathrm{a}_{1011}\right)=(59,59-10)=49$

$\mathrm{LT}_{9}=\operatorname{MIN}\left(\mathrm{LT}_{10}, \mathrm{LT}_{10}-\mathrm{a}_{910}\right)=(49,49-28)=21$

$\mathrm{LT}_{8}=\operatorname{MIN}\left(\mathrm{LT}_{9}, \mathrm{LT}_{9}-\mathrm{a}_{89}\right)=(21,21-10)=11$

$\mathrm{LT}_{7}=\mathrm{MIN}\left(\mathrm{LT}_{8}, \mathrm{LT}_{8}-\mathrm{a}_{78}\right)=(11,11-1)=10$

$\mathrm{LT}_{6}=\operatorname{MIN}\left(\mathrm{LT}_{7}-\mathrm{a}_{67}, \mathrm{LT}_{11}-\mathrm{a}_{611}\right)=(10-0,59-1)=10$

$\mathrm{LT}_{5}=\operatorname{MIN}\left(\mathrm{LT}_{11}, \mathrm{LT}_{11}-\mathrm{a}_{511}\right)=(59,59-1)=58$

$\mathrm{LT}_{4}=\mathrm{MIN}\left(\mathrm{LT}_{5}-\mathrm{a}_{45}, \mathrm{LT}_{7}-\mathrm{a}_{47}\right)=(58-2,10-0)=10$

$\mathrm{LT}_{3}=\mathrm{MIN}\left(\mathrm{LT}_{6}, \mathrm{LT}_{6}-\mathrm{a}_{36}\right)=(10,10-8)=2$

$\mathrm{LT}_{2}=\mathrm{MIN}\left(\mathrm{LT}_{4}, \mathrm{LT}_{4}-\mathrm{a}_{24}\right)=(10,10-2)=8$

$\mathrm{LT}_{1}=\operatorname{MIN}\left(\mathrm{LT}_{2}-\mathrm{a}_{12}, \mathrm{LT}_{3}-\mathrm{a}_{13}\right)=(8-2,2-2)=0$ 




FIGURE 8: NETWORK WITH EARLIEST AND LATEST TIMES

We compute the slack times, $\mathbf{S i j}$, for each activity. To do this we will use the formula Sij= Lj-Ei-Dij.

So for example to calculate. $\quad$ S24 (Slack time for activity C) $=$ L2-E4-D24 $=8-3-2=3$

So $\mathbf{S 2 4}=\mathbf{3}$, which means that activity can be delayed for 3 days and it will not make the activity late. Once we compute the slack time for all activities we can now identify the critical activities, which are all activities with a slack time $=0$. The critical path is identified in the red line below.

-TABLE 2: SLACK TIME FROM THE LATEST AND EARLIEST TIME

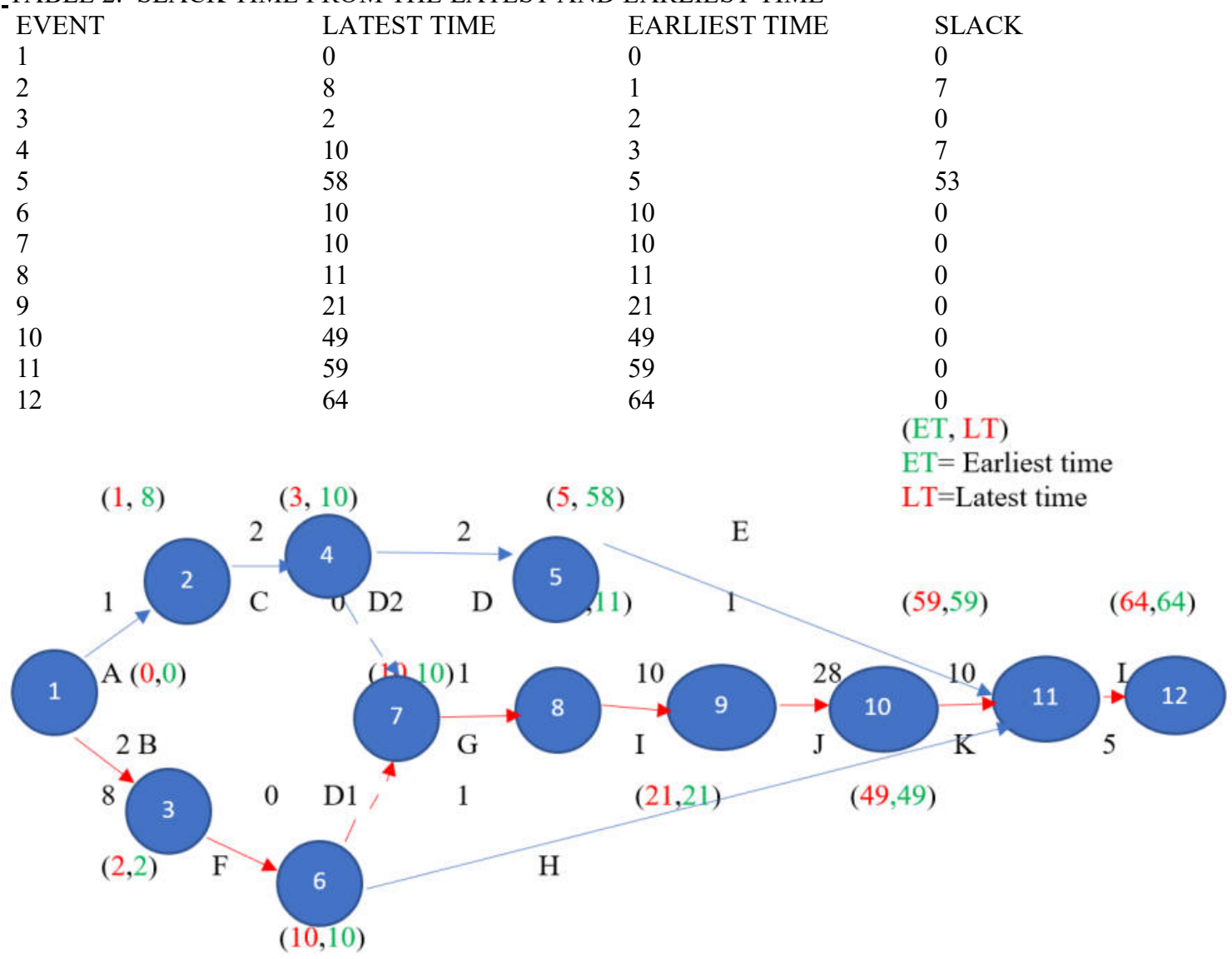

FIGURE 9: NETWORK WITH CRITICAL PATH

We now have some very valuable information. The critical path is $(1,3)$-> $(3,6)->(6,7)->(7,8)->(8,9)->(9,10)->(10,11)->(11,12)$. 
Activities that can run late (activities with a slack time 0) are activities A, C, D2, D, E, and $\mathbf{H}$. The completion time of our project $=\mathbf{6 4}$ days.

\subsection{PROGRAM EVALUATION AND REVIEW TECHNIQUE (PERT) METHOD}

Using the PERT method our activity chart would need three deterministic time for duration of the project shown in table below.

\section{TABLE 3: PERT ACTIVITY}

\section{ACTIVITY DESCRIPTION}

$\begin{array}{lll}\text { A } & \text { Site Clearing and Levelling } & 1,1,2 \\ \text { B } & \text { Excavation } & 1,2,2 \\ \text { C } & \text { Pouring of Foundation's Concrete } & 2,2,3 \\ \text { D } & \text { Setting Footings } & 1,2,3 \\ \text { E } & \text { Casting of Concrete Damp Proof } & 1,1,2 \\ & \text { Cause Floor } & \\ \text { F } & \text { Laying of Fish Pond Wall } & 4,8,9 \\ \text { G } & \text { Installation of Water Supply into the } & 1,1,2 \\ & \text { Pond from the Dam } \\ \text { H } & \text { Back Filling the Surroundings of the } & 1,1,1 \\ & \text { Fish Pond } \\ \text { I } & \text { Plastering } \\ \text { J } & \text { Curing of Plastering } & 7,10,12 \\ \text { K } & \text { Erection of Outlet Water Pipe } & 28,28,33 \\ \text { L } & \text { Net Cover } & 8,10,12 \\ \end{array}$

for activity $\mathbf{H}$, Back Filling the Surroundings of the Fish Pond, the duration is $\mathbf{1}$ for optimistic, most likely, and pessimistic times. This implies an activity that will always take 1 day regardless of the three estimates. We estimate the days for the pessimistic time and optimistic time, so when we calculate the mean using our formula

$\boldsymbol{\mu}=\left(\mathbf{a}^{\mathbf{a}+\mathbf{m}+\mathbf{b}} / \mathbf{6}\right)$ for each activity we will get the most likely time for that activity as the result. We calculated the standard deviation and variance using the formula for standard deviation $\sigma=(\mathbf{b - a} / 6)$ and the variance being $\sigma^{2}$. We will calculate the $\sigma_{13}$ and $\operatorname{Var13}$ for activity $B$ as followed: $\sigma_{13}=\mathbf{2 - 1 / 6}=1 / 6=0.167$ and $\quad \operatorname{Var13}=\left(\sigma_{13}\right)^{2}$ $\approx \mathbf{0 . 0 2 8}$

\section{COMPUTATION OF THE MEAN VALUES:}

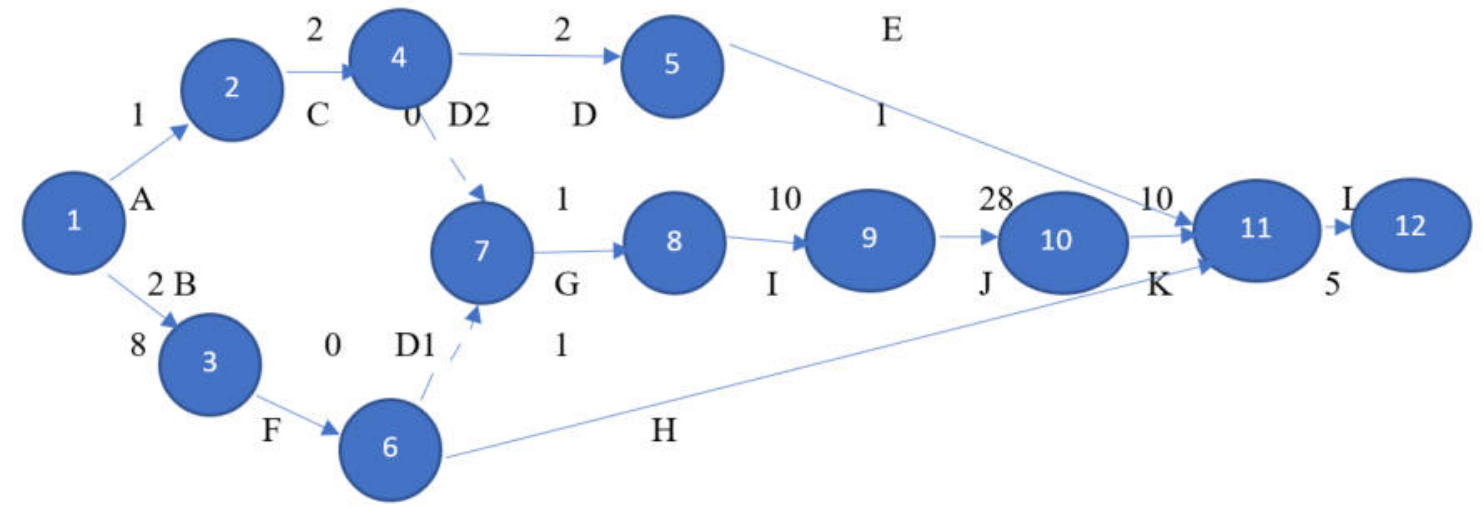

FIGURE 10: NETWORK FOR THE COMPUTATION OF MEAN VALUE USING PERT 
The table below shows the mean and variance using PERT

TABLE 4 : Showing mean and variance using PERT

$\begin{array}{llll}\text { ACTIVITY } & \text { I-J } & \text { MEAN } & \text { VARIANCE } \\ \text { A } & 1-2 & 1.17 & 0.03 \\ \text { B } & 1-3 & 1.83 & 0.03 \\ \text { C } & 2-4 & 2.17 & 0.03 \\ \text { D1 } & 6-7 & 0.00 & 0.00 \\ \text { D2 } & 4-7 & 0.00 & 0.00 \\ \text { D } & 4-5 & 2.00 & 0.11 \\ \text { E } & 5-11 & 1.17 & 0.03 \\ \text { F } & 3-6 & 7.50 & 0.69 \\ \text { G } & 7-8 & 1.10 & 0.03 \\ \text { H } & 6-11 & 1.00 & 0.00 \\ \text { I } & 8-9 & 9.83 & 0.83 \\ \text { J } & 9-10 & 28.83 & 0.83 \\ \text { K } & 10-11 & 10.00 & 0.67 \\ \text { L } & 11-12 & 5.00 & 0.67\end{array}$

The next step is the calculation of the Mean of the path and the standard deviation of the path.



FIGURE 11: PERT NETWORK

Mean of the path is simply just adding the mean of each activity till we get to a certain node. For example, if we wish to calculate the Mean of the Path to node 4, we would simply add

$$
1.17+2.17=3.34
$$

Likewise, the standard deviation of the path.



FIGURE 12: PERT NETWORK SHOWING THE CRITICAL PATH 


\begin{tabular}{|c|c|c|c|c|c|c|c|}
\hline NODE & LONGEST PATH & $\begin{array}{l}\text { PATH } \\
\text { MEAN }\end{array}$ & $\begin{array}{l}\text { PATH } \\
\text { STANDARD } \\
\text { DEVIATION }\end{array}$ & Tij & Zij & $\mathbf{P}\{\mathbf{Z} \leq \mathrm{Zij}\}$ & $\%$ \\
\hline 3 & $1-3$ & 1.17 & 0.17 & 2 & 4.88 & 0.9997 & $100 \%$ \\
\hline 6 & $1-3-6$ & 8.67 & 0.85 & 10 & 1.57 & 0.9418 & $94 \%$ \\
\hline 7 & $1-3-6-7$ & 8.67 & 0.85 & 11 & 2.74 & 0.9969 & $100 \%$ \\
\hline 11 & $1-3-6-7-8-9-10-11$ & 58.43 & 1.76 & 49 & -5.36 & 0.0003 & 0 \\
\hline 12 & $1-3-6-7-8-9-10-11-12$ & 63.43 & 1.94 & 64 & 0.29 & 0.3859 & $39 \%$ \\
\hline 12 & $1-3-6-7-8-9-10-11-12$ & 63.43 & 1.94 & 66 & 1.33 & 0.9082 & $91 \%$ \\
\hline 12 & $1-3-6-7-8-9-10-11-12$ & 63.43 & 1.94 & 68.5 & 2.61 & 0.9955 & $100 \%$ \\
\hline 12 & $1-3-6-7-8-9-10-11-12$ & 63.43 & 1.94 & 68 & 2.36 & 0.9909 & $99 \%$ \\
\hline
\end{tabular}

TABLE ANALYSIS INTERPRETATION

The table gives Tij which is the Time in which we know the probability of completing the project. As noted in the final row, the probability of completing the project in 68 days is $99 \%$ which $1 \%$ shy off $100 \%$ which mean the project will be completed before the $68^{\text {th }}$ day, even after taking into consideration of the worst case scenario.

\section{CONCLUSION}

Network analysis that comprises of two methods namely CPM and PERT has been used as the major tool to analyse the number of days it will take to complete the construction of Fish pond in Oke-Ogun River Basin Development Authority, based on the analysis so far, 64 days was arrived at for the completion of the construction using CPM method while 68 days with $99 \%$ probability was arrived at under the analysis using PERT method. In deciding which of the method is best suitable for the construction of the fish pond, PERT serve as the best method due to the fact that it considers the Pessimistic Time (longest time possible and can be seen as usual delay) and Optimistic Time (shortest time possible if things go perfectly) as well as the probability [which is $99 \%$ ] of completing the task within a specific time.

\section{RECOMMENDATION}

Based on the analysis and results, the would be users and managers of industry can use this laudable research as benchmark in carrying out their study from the feasibility stage, planning stage to the other stages so as to have a good practical target towards the completion of the project as planned.

\section{REFERENCES}

Abbasi, G.Y., and Arabiat, Y.A. (2001). A heuristic to maximize the net present value for resource-constrained project scheduling problems. Project Management Journal., 32(2), 17-24.

Ajiboye, S. A. (2011). Measuring process effectiveness using cpm/pert. International Journal of Business and Management., 6(6), 286-295.

Alcaraz, J., and Marota, C., (2001). “A robust genetic algorithm for resource allocation in project scheduling. Annals of Operations Research., 102, 83-109.

Al Fawzan, M., and Haouari, M., (2005). A bi-objective model for robust resource constrainedproject scheduling. International Journal of Production Economics, 96, 175-187.

Alvarez-Valdes, R., and Tamarit, J. M., (1989). Heuristic algorithms for resource constrained project scheduling: A view and an empirical analysis. In R. Slowinski and J. Weglarz, editors, Advances in project scheduling, 113-134, Elsevier, Amsterdam, the Netherlands.

Artigues, C.,Michelon, P., and Reusser, S., (2003). Insertion techniques for static and dynamic resource constrained project scheduling., European J. of Operational Research., 149, 249-267.

Blazewicz, J., Lenstra, J.K., and Rinnooy, A.H.G.(1983). Scheduling subject to resource constraints: Classification and complexity. Discrete Applied Mathematics., 5, 11-24.

Bell, C.E., and Park, K. (1990). Solving resource-constrained project scheduling problems by A* search., Naval Research Logistics., 37, 61-84.

Bean, J. (1994). Genetic algorithms and random keys for sequencing and optimization., ORSA Journal on Computing., 6(2), 154-160.

Bedworth, D.D., and Bailey, J.E. (1982). Integrated Production Control Systems Management, Analysis, Design. Wiley, New York.

Boctor, F.F.(1993). Heuristic for scheduling projects with resource restrictions and several resource-duration modes. International Journal of production Research., 31(11), 2547-558.

Chan, W.T., and Chua, D.K.H. (1996). Construction resource scheduling with genetic algorithms. Journal of Construction Engineering and Management., 122(2), 125-32.

Chapman, C., and Ward, S.,(2000). Estimation and evaluation of uncertainty: a minimalist first pass approach." 
International Journal of Project Management., 18, 369-383.

Cho, J. H., and Kim, Y. D. (1997). A Simulated Annealing Algorithm for Resource-Constrained Project Scheduling Problems. The Journal of the Operational Research Society., 48(7), 736-744.

Christofides, N., Alvarez-Valdes, R., and Tamarit, J. M. (1987). Project Scheduling with Resource Constraints: A Branch and Bound Approach. European Journal of Operational Research., 29, 262-273.

Davis, E. W., and Patterson, J . H. (1975).A comparison of heuristic and optimum solutions in resource-constrained project scheduling. Management Science., 21, 718- 722.

Demeulemeester, E. and W. Herroelen. (1996b). An Efficient Optimal Solution Procedure for the Preemptive Resource-Constrained Project Scheduling Problem. European Journal of Operational Research., 90, 334348.

Dobin, B. N. (1985). Bounding the project completion time distribution in PERT networks.Operation Res., 33, $862-881$.

Ellen. J., and John. D. (1993). An examination of resource policies for the multi-resource problem. International J. Operations and Production Management., 13(5), 51-76.

Eshelman, L., and Caruana, R., Schaffer, D. , (1989). Biases in the Crossover Landscape. Proceedings of the Third International Conference on Genetic Algorithms, ed. J. D. Schaffer, San Mateo, CA: Morgan Kaufmann,1019.

Feng, C. W., Liu, L., and Burns, S. A. (1997). Using genetic algorithms to solve construction time-cost trade-off problems. J. Comp. Civ. Engrg., ASCE, 11(3), 184-189.

arrington, MA.

Hartmann S., and Drexl A. (1998). Project scheduling with multiple modes: a comparison of exact algorithms. Networks, 32, 283-97.

Hegazy, T., and Kassab, M. (2003). Resource optimization using combined simulation and genetic algorithms. Journal of Construction Engineering and Management, 129(6), 698705.

Herroelen W. S., Demeulemeester E., and De Reyck B. (1998). Resource-constrained project scheduling - a survey of recent developments. Computers \& Operations Research., 25(4), 279-302.

Hindi, K.S., Yang, H., and Fleszar, K. (2002). An evolutionary algorithm for resource constrained project scheduling. IEEE Transactions on Evolutionary Computation., 6(5), 512-518.

Holland, J. H. (1975). Adaptation in natural and artificial systems. University of Michigan Press, Ann Arbor, Mich.

Kolisch, R., Sprecher, A., Drexl A. (1995). "Characterization and generation of a general class of resourceconstrained project scheduling problems." Management Science., 41(10), 1693-1703.

Krishnamoorthy M.S., and Deo N. (1979). "Complexity of the minimum-dummy-activities problem in a PERT network." Networks., 9, 189-94.

Kurtulus I., and Davis E. (1982). "Multi-project scheduling: categorization of heuristic rules performance." Management Science., 28, 161-172.

Lai, Y. J. , Liu, T. Y. , and Hwang, C. L. (1994). "TOPSIS for MODM ", European Journal of Operational Research, 76 (3) , 486-500.

Leon V.J., and Balakrishnan R. (1995). "Strength and Adaptability of Problem-Space Based Neighborhood for Resource-Constrained Scheduling.", OR Spektrum., 17, 173-182.

Pulat, P.S., and Horn, S.J. (1996). "Time-resource tradeoff problem [project scheduling]." IEEE Trans.Eng. Manage., 43, 411-417.

Schirmer, A., (1999). " Resource constrained project scheduling: An evaluation of adaptive control schemes for parameterized sampling heuristic.” I. J. Oper. Prod. Mang., 39(7),1343-1365.

Slowinski, R. (1980). "Two Approaches to Problems of Resource Allocation among Project Activities-A Comparative Study." The Journal of the Operational Research Society., 31(8), 711-723.

Thomas P. R., and Salhi, S. (1998)., “ A tabu search approach for the resource constrained project scheduling problem., Journal of heuristic., 4, 123-139.

Toklu, Y.C. (2002). "Application of genetic algorithm to construction schedule with or without resource constraints., Canadian Journal of Civil Engineering., 29(3), 422-429.

Tormos, P., and Lova, A. (2001). "A Competitive Heuristic Solution Technique for Resource Constrained Project Scheduling.” Annals of Operations Research., 102, 65-81.

Zahn, J. (1994). "Heuristics for Scheduling Resource-Constrained Projects in MPM Networks"European Journal of Operational Research, 76, 192-205.

Zhang, H., Li, H., and Tam, C. M. (2006). "Permutation-based particle swarm optimization for resourceconstrained project scheduling.” J. Computer. Civil Engineering, 20(2), 141-149.

Zhu D, and Padman R. (1999). " A meta-heuristic scheduling procedure for resource-constrained projects with cash Cows." Naval Research Logistics, 46, 1-18. 